\title{
Access to care and outcomes for neuroendocrine tumours: does socioeconomic status matter?
}

J. Hallet MD MSc, ${ }^{* \dagger \ddagger \S}$ N.G. Coburn MD MPH, ${ }^{\dagger \neq \S}$ S. Singh MD MPH, ${ }^{* \neq \S \|}$ K. Beyfuss BSc, ${ }^{\S}$ S. Koujanian MD, ${ }^{\S}$ N. Liu MSc, ${ }^{\ddagger}$ and C.H.L. Law MD MPH*广§

\begin{abstract}
Introduction Neuroendocrine tumours (NETS) are a poorly understood malignancy lacking standardized care. Differences in socioeconomic status (SES) might worsen the effect of non-standardized care. We examined the effect of SES on NET peri-diagnostic care patterns and outcomes.
\end{abstract}

Methods In this population-based cohort study, NET cases identified from a provincial cancer registry (1994-2009) were divided into low (1st and 2nd income quintiles) and high (3rd, 4th, and 5th quintiles) ses groups. We compared peri-diagnostic health care utilization ( -2 years to +6 months), metastatic recurrence, and overall survival (os) between the groups.

Results Of 4966 NET patients, 38.3\% had a low sEs. Neither the primary NET sites $(p=0.15)$, nor the metastatic presentation $(p=0.31)$ differed. Patients with low ses had a higher mean number of physician visits $(20.1 \pm 19.9$ vs. $18.1 \pm 16.5, p=0.001)$ and imaging studies ( $56 \pm 50$ vs. $52 \pm 44, p=0.009)$ leading to the NET diagnosis. Rates of primary tumour resection $(p=0.14)$, hepatectomy $(p=0.45)$, systemic therapy $(p=0.38)$, and liver embolization $(p=0.13)$ did not differ with ses. In the low-ses group, metastatic recurrence was more likely ( $41.1 \%$ vs. $37.6 \%, p=0.01)$ during a median follow-up of 61.7 months, and the 10 -year os was inferior $(47.1 \%$ vs. $52.2 \%, p<0.01)$. Low SES was associated with worse os (hazard ratio: 1.16; $95 \%$ confidence interval: 1.06 to 1.26) after adjustment for age, sex, comorbidity burden, primary NET site, and rural living.

Conclusions Low SES was associated with more physician visits and imaging before a NET diagnosis, but not with more advanced stage at presentation nor with an effect on the pattern of therapy. Long-term outcomes were inferior in the low-SEs group. These data can help to inform the design of health care delivery for NETS.

Key Words Neuroendocrine tumours, carcinoids, socioeconomics, income, outcomes

Curr Oncol. 2018 Oct;25(5):e356-e364

www.current-oncology.com

\section{INTRODUCTION}

Neuroendocrine tumours (NETS) are malignancies that are most commonly found in the gastrointestinal and bronchopulmonary tracts, but that can also arise in other locations such as the ovaries, thymus, or kidney ${ }^{1,2}$. Traditionally considered rare, these tumours have been rising in incidence in recent decades ${ }^{1-4}$. Because of their unique indolent biology, leading to prolonged survival even in the setting of metastatic disease, NETs are now more prevalent than better-known malignancies, including gastric, pancreatic, and esophageal cancers ${ }^{2}$. They represent a unique burden to the health care system by combining long survival and potentially significant systemic symptoms from hormone secretion in functional tumours ${ }^{5,6}$.

Because of nonspecific signs and symptoms, lack of awareness and knowledge in the medical community, and the uncommon nature of the malignancy, a diagnosis of NET can be delayed for up to 7 years ${ }^{5,6}$. Tackling that lag in diagnosis has been identified as a priority in NET management to eventually improve outcomes ${ }^{7}$. Although clinical trials have recently been successfully conducted 
in the medical management of NETs, very little is currently known about how care is delivered for NETs and how that care affects outcomes, particularly in the pre-diagnostic period. To determine how best to design care strategies for NETS, identifying and understanding areas of potential disparities in management and outcomes is required.

Factors at both the population and delivery system levels can influence health care utilization for cancer ${ }^{8,9}$. Socioeconomic status (SEs) is related to health services use, patterns of care, and outcomes for common malignancies such as head-and-neck, lung, colon, and breast cancers ${ }^{10-13}$. The influence of SES on NET diagnosis and outcomes remains undefined.

In this population-based study, we sought to define the effect of SEs on health care utilization leading to a NET diagnosis and on long-term outcomes for NET patients. We hypothesized that low ses would be associated with a lesser use of health services before a NET diagnosis and inferior survival.

\section{METHODS}

\section{Study Design}

This population-based cohort study used health care administrative data and was approved by the Research Ethics Board at Sunnybrook Health Sciences Centre. The research was conducted and reported in accord with the RECORD statement ${ }^{14}$.

\section{Study Population}

All patients benefited from universally accessible, publicly funded health care coverage through oHIP (the Ontario Health Insurance Plan). All residents of the province are eligible for OHIP coverage after 3 months of residency. The population in the province increased from 8,054,030 in 1994 to $10,004,048$ in 2009 . Our study considered all patients having a valid OHIP number during the period 1 April 1994 to 31 March 2009.

\section{Data Sources}

A study cohort was created by linking administrative datasets housed at the Institute for Clinical Evaluative Sciences (ICES). The Ontario Cancer Registry includes all patients with a cancer diagnosis (excluding non-melanoma skin cancer) in Ontario since $1964^{15,16}$. The reliability of its data has previously been ascertained and reported ${ }^{16-18}$. The Registered Persons Database contains vital status and demographic data for all individuals covered under oHIP ${ }^{19}$. Information about health services use is included in the Canadian Institute for Health Information's Discharge Abstract Database (acute inpatient hospitalizations), the National Ambulatory Care Reporting System (same-day surgery admissions, emergency room visits, and oncology clinic visits), and the OHIP Claims Database (billings from health care providers, including physicians, groups, laboratories, and out-ofprovince providers ${ }^{20}$. The databases have all been validated for a variety of diagnoses and services ${ }^{20}$. The datasets were linked using unique encoded identifiers and analyzed at ICES. The research team's analyst (NL) had complete access to all datasets used in the study to create the study cohorts, proceed to linkage, and perform the analyses.

\section{Study Cohort}

For the study period, diagnoses were classified according to the International Classification of Diseases [9th revision (ICD-9)] for the primary disease site and to the International Classification of Diseases for Oncology (ICD-O) for morphology $\mathrm{y}^{21,22}$. All adult patients with a new diagnosis of NET during the study period were identified by those codes in the Ontario Cancer Registry, using a strategy previously reported by our group (Appendix A) ${ }^{1,23}$.

\section{Outcomes Measures}

Advanced stage at diagnosis was defined as metastatic disease at presentation (metastasis code in the same episode as the first NET diagnosis).

Pre-diagnostic health care resources utilization was captured based on three measures: physician encounters, emergency department visits, and imaging studies. Physician encounters were captured using OHIP billing claims and were subdivided into specialist and general practitioner encounters. Imaging studies were subdivided based on the type of imaging: simple radiography, ultrasonography, computed tomography imaging, magnetic resonance imaging, and nuclear medicine imaging. Those variables were defined for the 2 years preceding the NET diagnosis.

Initial therapy was captured as use of surgery (primary tumour resection, liver resection), systemic chemotherapy, radiation therapy, and liver embolization. The period from 60 days before to 60 days after the NET diagnosis was considered to capture therapies that might have been undertaken before a tissue diagnosis was made (for example, emergency surgery yielding a NET diagnosis on pathology). Visits to surgery and medical oncology services were also abstracted for that period.

Finally, overall survival (os) from the date of NET diagnosis was computed using the date of death up to $31 \mathrm{March}$ 2010. Patients with a diagnosis of non-NET cancer within 60 days of the NET diagnosis were excluded from the survival analysis. Patients were followed until date of death, date of last contact, 10 years after the NET diagnosis, or 31 March 2010, whichever came first.

\section{Exposure}

The main exposure of interest was SEs. The patient's SES was assessed using an ecologic measure of income quintile based on the median income associated with the patient's postal code of residence in national census data ${ }^{24,25}$. Low SES was defined as the 1st and 2nd income quintiles, and high ses as the 3rd, 4th, and 5th income quintiles.

\section{Covariates}

Age and sex were abstracted from the Registered Persons Database. Rural living was determined as a postal code indicating residence in a rural area based on the national census definition of a community of fewer than 10,000 people $^{26}$. Aggregated clinical groups were used to define major physical comorbidities (The Johns Hopkins ACG System: The Johns Hopkins University, Baltimore, MD, U.S.A.). The resource utilization band was computed based on aggregated clinical groups to assess expected health care requirements ${ }^{27}$. 
The NETs were subdivided by primary tumour site into bronchopulmonary (ICD-9 code 162), gastroenteric (ICD-9 codes 151-154), pancreatic (ICD-9 code 157), and others. Recurrent metastatic disease was defined as metastases occurring after the initial diagnosis (metastasis code after the episode of the first NET diagnosis, Appendix A).

Relevant demographic and clinical characteristics were identified $a$ priori as potential confounders of the relationship between ses and outcome. The variables were selected based on clinical relevance (markers of complexity of cancer care) and existing literature (known relationship with variation in health care delivery). The most parsimonious set of covariates was selected to maintain adequate study power. The covariates ultimately included were these: age, sex, rural living, major comorbidity, and primary tumour site.

\section{Statistical Analysis}

Descriptive analysis was used to define baseline characteristics and outcomes. Categorical variables are reported as absolute numbers and proportions, and continuous variables are reported as means with standard deviation. Use of health services was reported as the proportion of patients using a service and as the mean use of that service per patient during the relevant period. Comparison testing used the chi-square test or $t$-test as appropriate. The Kaplan-Meier method was used for os analysis ${ }^{28}$, and os curves based on sEs were compared using the log-rank test. Multivariable regression models were constructed to assess the effect of ses on advanced disease presentation (logistic regression) and os (Cox regression), while adjusting for other baseline characteristics defined $a$ priori as previously described.

Statistical significance was set at $p \leq 0.05$. All analyses were conducted using the SAS Enterprise Guide software application (version 6.1: SAS Institute, Cary, NC, U.S.A.).

\section{RESULTS}

A first NET diagnosis was identified in 4966 patients during the period of interest. Table I presents the characteristics of the included patients, stratified by ses. No difference in rural living or resource utilization band was observed between the low- and high-sEs groups. Major comorbidity was statistically more likely in patients with a low SES $(p=0.002)$.

The proportion of patients diagnosed with an advanced-stage NET did not differ between the low-sEs and high-sEs groups (19.2\% vs. $18.0 \%, p=0.307)$. After adjusting for age, sex, primary tumour site, rural living, and major comorbidity, low ses was not associated with advanced stage at presentation [odds ratio: 1.05; 95\% confidence interval (CI): 0.91 to 1.22 ].

Figure 1 shows the number of physician encounters in the 2 years preceding the NET diagnosis by SES group. The mean number of visits to any physician was higher for patients with a low SES $(p=0.001)$. That number was driven by more frequent visits to general practitioners $(p<0.001)$. More patients with a low sEs visited the emergency department $(63.6 \%$ vs. $58.0 \%, p<0.01)$.

Overall, patients with a low sEs underwent more imaging studies, with the mean number of studies in the low-SES
TABLE I Characteristics of the study patients

\begin{tabular}{|c|c|c|c|}
\hline \multirow[t]{2}{*}{ Variable } & \multicolumn{2}{|c|}{ Patient group $[n(\%)]$} & \multirow{2}{*}{$\begin{array}{c}p \\
\text { Value }\end{array}$} \\
\hline & Low SES & High SES & \\
\hline Patients & 1901 & 3065 & \\
\hline \multicolumn{4}{|l|}{ Age group } \\
\hline 19-50 Years & $459(24.1)$ & $819(26.7)$ & 0.027 \\
\hline 51-60 Years & $428(22.5)$ & $745(24.3)$ & \\
\hline $61-70$ Years & $488(25.7)$ & $734(23.9)$ & \\
\hline$\geq 71$ Years & $526(27.7)$ & $767(25.0)$ & \\
\hline Male sex & $921(48.4)$ & $1521(49.6)$ & 0.42 \\
\hline Rural living & $283(14.9)$ & $387(12.6)$ & 0.092 \\
\hline \multicolumn{4}{|l|}{ Resource utilization band } \\
\hline 0 & $16(0.8)$ & $13(0.4)$ & 0.13 \\
\hline 1 & $17(0.9)$ & $33(1.1)$ & \\
\hline 2 & $74(3.9)$ & $147(4.8)$ & \\
\hline 3 & $850(44.7)$ & $1416(46.2)$ & \\
\hline 4 & $547(28.8)$ & $868(28.3)$ & \\
\hline 5 & $397(20.9)$ & $588(19.2)$ & \\
\hline Major comorbidity & $1478(77.7)$ & $2261(73.8)$ & 0.002 \\
\hline \multicolumn{4}{|l|}{ Primary tumour site } \\
\hline Bronchopulmonary & $484(25.5)$ & $734(23.9)$ & 0.15 \\
\hline Gastroenteric & $873(45.9)$ & $1480(48.3)$ & \\
\hline Pancreatic & $177(9.3)$ & $312(10.2)$ & \\
\hline Other & $367(19.3)$ & $539(17.6)$ & \\
\hline
\end{tabular}

$\mathrm{SES}=$ socioeconomic status.

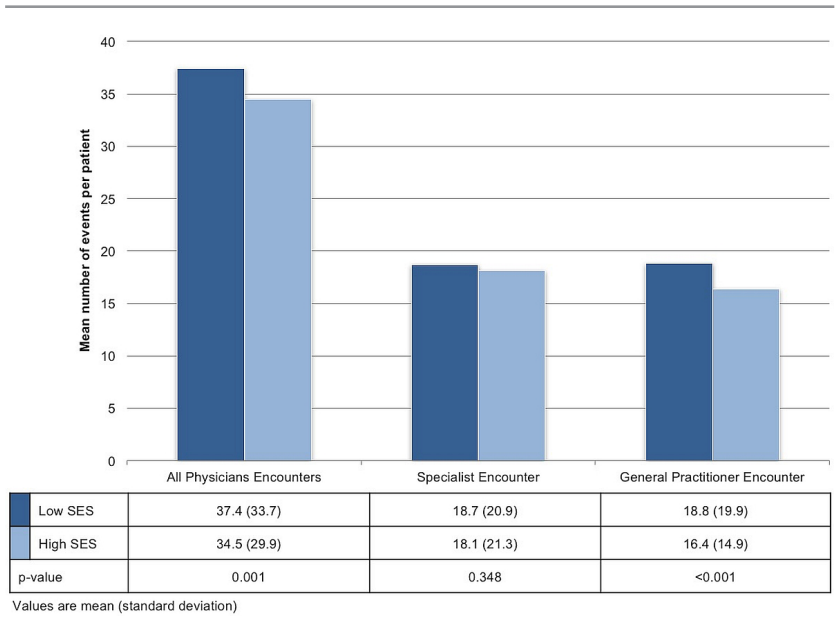

FIGURE 1 Mean number of physician encounters in the 2 years before the diagnosis of neuroendocrine tumour, stratified by socioeconomic status (SES).

group being $56.1 \pm 50.0$ compared with $51.9 \pm 44.5$ in the high-ses group ( $p=0.003$ ). Figure 2 depicts, in detail, the use of imaging studies. Magnetic resonance imaging was used less often in patients with a low sEs than in those with a high SES $(p=0.042)$. 


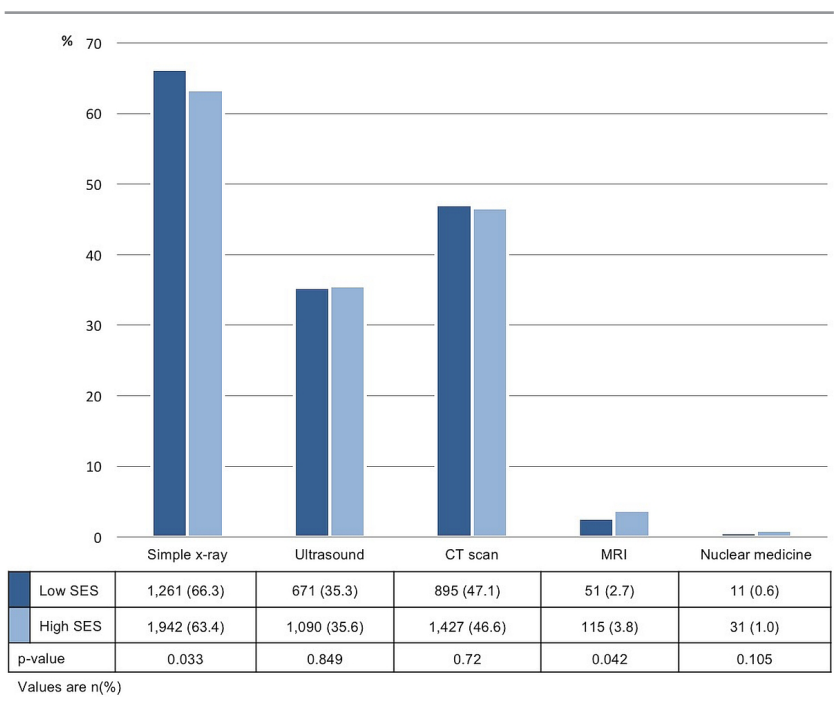

FIGURE 2 Use of imaging studies in the 2 years before the diagnosis of neuroendocrine tumour, stratified by socioeconomic status (SES). CT = computed tomography; MRI = magnetic resonance imaging.

Around the time of NET diagnosis ( 60 days before and 60 days), $69.5 \%$ of patients with a low ses and $69.4 \%$ with a high ses had a surgical consultation ( $p=0.964)$, and $26.8 \%$ and $27.6 \%$ respectively met with a medical oncologist $(p=0.569)$. Figure 3 presents treatments received during the period of interest. The most common treatment was resection of the primary tumour in $44.3 \%$ of patients with low SES and $46.4 \%$ of patients with high sEs. No difference based on ses was observed in receipt of surgery for the primary tumour or liver metastases, liver embolization, chemotherapy, or radiation therapy.

Mean follow-up was $61.7 \pm 42.8$ months. A subsequent non-NET cancer occurred in 294 patients (5.9\%), who were excluded from the survival analysis. During the follow-up period, metastatic recurrence was more likely in the lowSES group ( $41.1 \%$ vs. $37.6 \%, p=0.013)$. Figure 4 presents the os analysis. The 10-year os was inferior in the low-SES group at $47.1 \%$ (95\% cr: $44.6 \%$ to $49.7 \%$ ) compared with $52.2 \%$ (95\% CI: $50.2 \%$ to $54.4 \%$ ) in the high-ses group. Low SES was independently associated with a higher likelihood of mortality after adjusting for age, sex, rural living, major comorbidity, and primary tumour site (hazard ratio: 1.16; $95 \%$ CI: 1.06 to 1.26 ).

\section{DISCUSSION}

Better understanding of potential disparities underlying care and outcomes in NET is crucial for improving health care delivery in a malignancy lacking a clear pathway to diagnosis and a standard of care. Our study outlines, for the first time, the effect of the ses gradient on health care utilization and outcomes for this uncommon malignancy in a large comprehensive contemporary cohort. Low SES was associated with a higher number of physician encounters and imaging studies leading to the NET diagnosis-a circumstance that did not affect stage at diagnosis (advanced stage at presentation: $19.2 \%$ vs. $18.0 \% ; p=0.307$ ) or the pattern of therapy (no difference in initial therapy).

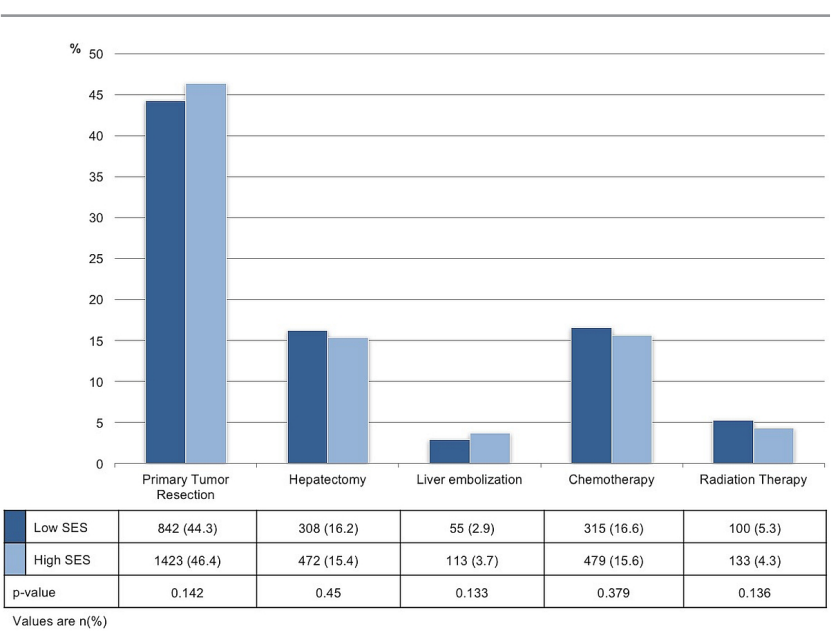

FIGURE 3 Initial therapy from 60 days before to 60 days after the diagnosis of neuroendocrine tumour, stratified by socioeconomic status (SES).

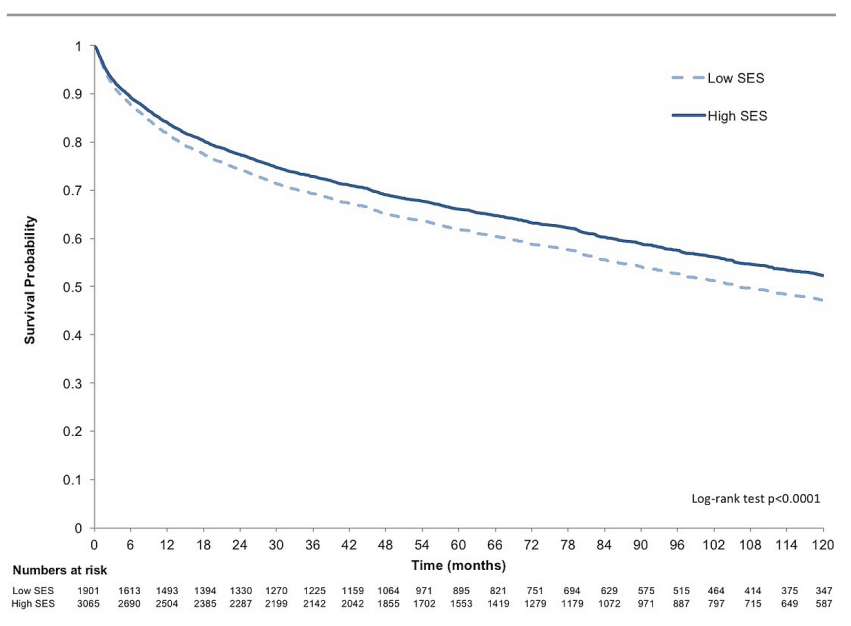

FIGURE 4 Overall survival for patients with neuroendocrine tumour, stratified by socioeconomic status (SES).

However, long-term outcomes were inferior for patients with a low SES, as evidenced by higher likelihoods of metastatic recurrence and inferior os. Patients with a low SES experienced a $16 \%$ increased risk of death (hazard ratio: 1.16 ; $95 \%$ cr: 1.06 to 1.26 ).

Socioeconomic disparities in cancer care and outcomes have been reported for other, more common malignancies ${ }^{12,13}$. Despite universal publicly funded health care systems designed to provide equitable care for all, SES is independently associated with health status, including oncologic treatment outcomes ${ }^{11,29-32}$. Lower ses is associated with an increased cancer incidence and worse cancer patient survival in North American, European, and Australian jurisdictions ${ }^{12,32-37}$. That association between SES and outcomes resists variation in ses definitions and study designs, and shows a risk of mortality that is increased by a factor in the range of $1.5-5^{13}$.

The present study was not designed specifically to assess the numerous social and clinical determinants of 
outcomes. Outcome disparities related to sEs can originate from tumour, patient, and health system characteristics ${ }^{13}$. Our study did demonstrate different patterns in access to care: patients with a lower ses had more physician encounters and underwent more investigations before diagnosis.

It is unlikely that tumour biology differs solely based on sEs. However, it could be associated with rural environments, which are known to be associated with a higher incidence of NETS $^{23}$. However, no difference in rural living was observed in our SES groups. In the past, stage at diagnosis partly explained outcome differences in breast and colon cancers $^{13}$. The influence of stage varies based on cancer site and population type, does not entirely explain disparities, and was refuted in more recent analyse ${ }^{11,13,34,38}$. Moreover, the stage issue becomes less relevant in NETs, for which no screening method is available and a lag in diagnosis is common $^{5}$. There is no standardized pathway to a NET diagnosis, and earlier access to care might not result in faster diagnosis, as evidenced by the similar proportions of advanced-stage presentation in both ses groups in our study.

Patient characteristics such as comorbidities, nutrition status, social supports, the social stigma perception of cancer, and the individual perception of personal risk have all been suggested as potential explanations for disparities in outcomes with SES ${ }^{13,39-41}$. The application of resource utilization bands to capture expected health care needs based on baseline comorbidities did not identify differences between our ses groups. Differences in attitudes toward health care and support-seeking could be more relevant here, because those factors can affect access to care beyond the NET diagnosis ${ }^{13,42}$.

Our results indicate potential disparities in maintenance therapy and follow-up. They echo findings in patients with acute myocardial infarction, for whom low SES was independently associated with compromised functional recovery and increased mortality despite similar initial access to care cand $^{24,43}$. Beyond diagnosis and initial therapy, a focus on aftercare is required-an important factor in follow-up and longitudinal surveillance that could contribute to disparities in long-term outcomes. Beyond the effect of inequitable distribution of health facilities, patients with a low ses are also less likely to receive specific services ${ }^{24,30,44}$. Education, occupational stress, and social isolation can all contribute to outcome ${ }^{42,45}$. Access to and seeking specialized cancer care for a rare and unknown disease might be more difficult or not perceived to be needed in low-ses populations, adversely affecting outcomes $^{46-50}$. Because of indolent biology, NETs have a unique requirement to spread therapy over a prolonged natural history-a requirement that is as crucial as the initial treatments received. For an optimal outcome, patients must have to access the health system, but also be retained within it for years. Differences in follow-up and ongoing therapy can therefore explain the worse recurrence pattern and os associated with low sEs. Those observations become even more critical as disparities between income quintiles gradually increase. Larger gaps between sEs groups could worsen disparities in access to care and long-term outcomes if such issues are not addressed.

We acknowledge the limitations associated with using ICD-O codes to identify NETS, especially considering the heterogeneity of the disease. In addition, ICEs does not maintain data about pathology characteristics, and thus the population could not be further refined by tumour grade. The datasets used were not specifically collected to answer our research questions. In the absence of individual data, sEs was determined based on an ecologic measure; however, this proxy measure has been validated in previous population-based studies ${ }^{24,51,52}$.

Looking past the inherent challenges associated with population-based studies, the present appraisal is the first of the effect of SES on care and outcomes in NET. The universal health care system setting allowed for a comprehensive examination of patterns of care. Our analysis furthers the understanding of and informs the care processes for NETS. It suggests that, to improve outcomes for this malignancy, efforts should be made both to facilitate access to specialized care and to ensure specialized longitudinal care in vulnerable populations with NETs. Future efforts will focus on ascertaining the variability in regional health care delivery for NETs and the relation of any variability with diagnosis patterns and outcomes.

\section{CONCLUSIONS}

The present study describes the effect of ses on care and outcomes in NETS. Low SES was associated with more physician visits and imaging to reach diagnosis, but not with advanced-stage presentation or differences in initial therapy. Long-term outcomes were inferior for low-SEs patients, with more frequent metastatic recurrence and worse 10-year os. That pattern of ses affecting outcomes seems to be multifactorial and to be underlined by health care-seeking behaviours and the ability to maintain access to care throughout surveillance and to receive prolonged active care for a chronic malignancy. The data provide further insight for future efforts to enhance health care delivery by focusing on access to specialized care and to long-term maintenance therapy and surveillance.

\section{ACKNOWLEDGMENTS}

This study was supported by ICES, which is funded by an annual grant from the Ontario Ministry of Health and Long-Term Care (MонLтC). The opinions, results, and conclusions reported in this paper are those of the authors and are independent from the funding sources. No endorsement by ICES or the Ontario MOHLTC is intended or should be inferred. Parts of this material are based on data and information compiled and provided by the Canadian Institute for Health Information (CIHI). However, the analyses, conclusions, opinions, and statements expressed herein are those of the authors and not necessarily those of cinI. Parts of this material are based on data and information provided by Cancer Care Ontario (cco). The opinions, results, views, and conclusions reported in this paper are those of the authors and do not necessarily reflect those of cco. No endorsement by cco is intended or should be inferred.

Part of this work was presented as a poster at the Society of Surgical Oncology Annual Cancer Symposium; Boston, MA, U.S.A.; 2-5 March 2016; at the European Neuroendocrine Tumor Society Annual Meeting; Barcelona, Spain; 9-11 March 2016; at the North American Neuroendocrine Tumor Society annual meeting; Jackson, WY, U.S.A.; 30 September to 1 October 2016; and as oral presentation at the Canadian Surgery Forum; Toronto, ON; 8-10 September 2016. 


\section{CONFLICT OF INTEREST DISCLOSURES}

We have read and understood Current Oncology's policy on disclosing conflicts of interest, and we declare the following interests: DJH and SS have received speaker honoraria from Novartis Oncology and Ipsen. The remaining authors have no disclosures to make.

\section{AUTHOR AFFILIATIONS}

*Susan Leslie Clinic for Neuroendocrine Tumours, Odette Cancer Centre at Sunnybrook Health Sciences Centre, 'Department of Surgery, University of Toronto, ${ }^{\ddagger}$ Institute for Clinical Evaluative Sciences, ${ }^{\S}$ Sunnybrook Research Institute, "Department of Medicine, University of Toronto, ON.

\section{REFERENCES}

1. Hallet J, Law CH, Cukier M, Saskin R, Liu N, Singh S. Exploring the rising incidence of neuroendocrine tumors: a populationbased analysis of epidemiology, metastatic presentation, and outcomes. Cancer 2015;121:589-97.

2. Yao JC, Hassan M, Phan A, et al. One hundred years after "carcinoid": epidemiology of and prognostic factors for neuroendocrine tumors in 35,825 cases in the United States. J Clin Oncol 2008;26:3063-72.

3. Hauso O, Gustafsson BI, Kidd M, et al. Neuroendocrine tumor epidemiology: contrasting Norway and North America. Cancer 2008;113:2655-64.

4. Fraenkel M, Kim M, Faggiano A, de Herder WW, Valk GD on behalf of the Knowledge NETwork. Incidence of gastroenteropancreatic neuroendocrine tumours: a systematic review of the literature. Endocr Relat Cancer 2014;21:R153-63.

5. Modlin IM, Oberg K, Chung DC, et al. Gastroenteropancreatic neuroendocrine tumours. Lancet Oncol 2008;9:61-72.

6. Modlin IM, Kidd M, Latich I, Zikusoka MN, Shapiro MD. Current status of gastrointestinal carcinoids. Gastroenterology 2005;128:1717-51.

7. Modlin IM, Moss SF, Chung DC, Jensen RT, Snyderwine E. Priorities for improving the management of gastroenteropancreatic neuroendocrine tumors. J Natl Cancer Inst 2008;100:1282-9.

8. Kosteniuk JG, Dickinson HD. Tracing the social gradient in the health of Canadians: primary and secondary determinants. Soc Sci Med 2003;57:263-76.

9. Babitsch B, Gohl D, von Lengerke T. Re-revisiting Andersen's Behavioral Model of Health Services Use: a systematic review of studies from 1998-2011. Psychosoc Med 2012;9:Doc11.

10. Paszat LF, Mackillop WJ, Groome PA, Zhang-Salomons J, Schulze K, Holowaty E. Radiotherapy for breast cancer in Ontario: rate variation associated with region, age and income. Clin Invest Med 1998;21:125-34.

11. Groome PA, Schulze KM, Keller S, et al. Explaining socioeconomic status effects in laryngeal cancer. Clin Oncol (R Coll Radiol) 2006;18:283-92.

12. Booth CM, Li G, Zhang-Salomons J, Mackillop WJ. The impact of socioeconomic status on stage of cancer at diagnosis and survival: a population-based study in Ontario, Canada. Cancer 2010;116:4160-7.

13. Woods LM, Rachet B, Coleman MP. Origins of socio-economic inequalities in cancer survival: a review. Ann Oncol 2006;17:5-19.

14. Benchimol EI, Smeeth L, Guttmann A, et al. on behalf of the RECORD Working Committee. The reporting of studies conducted using observational routinely-collected health data (RECORD) statement. PLoS Med 2015;12:e1001885.

15. Robles SC, Marrett LD, Clarke EA, Risch HA. An application of capture-recapture methods to the estimation of completeness of cancer registration. JClin Epidemiol 1988;41:495-501.

16. Clarke EA, Marrett LD, Kreiger N. Cancer registration in Ontario: a computer approach. IARC Sci Publ 1991;:246-57.
17. Holowaty EJ, Dale D. The hospital-only project. Health Rep 1993;5:91-5.

18. Paszat L, Brundage M, Groome PA, Schulze K, Mackillop WJ. A population-based study of rectal cancer: permanent colostomy as an outcome. Int J Radiat Oncol Biol Phys 1999;45:1185-91.

19. Iron K, Zagorski BM, Sykora K, Manuel DG. Living and Dying in Ontario: An Opportunity for Improved Health Information. ICES Investigative Report. Toronto, ON: Institute for Clinical Evaluative Sciences; 2008.

20. Juurlink DN, Preyra C, Croxford R, et al. Canadian Institute for Health Information Discharge Abstract Database: A Validation Study. Toronto, ON: Institute for Clinical Evaluative Sciences; 2006.

21. World Health Organization (wHo). International Classification of Diseases for Oncology (ICD-O). Geneva, Switzerland: wHо; 1976.

22. World Health Organization (wно). Manual of the International Statistical Classification of Diseases, Injuries, and Causes of Death. Geneva, Switzerland: wно; 1977.

23. Hallet J, Law CH, Karanicolas PJ, Saskin R, Liu N, Singh S. Rural-urban disparities in incidence and outcomes of neuroendocrine tumors: a population-based analysis of 6271 cases. Cancer 2015;121:2214-21.

24. Alter DA, Naylor CD, Austin P, Tu JV. Effects of socioeconomic status on access to invasive cardiac procedures and on mortality after acute myocardial infarction. $N$ Engl J Med 1999;341:1359-67.

25. Wilkins R. Use of postal codes and addresses in the analysis of health data. Health Rep 1993;5:157-77.

26. du Plessis V, Beshiri R, Bollman RD, Clemenson H. Definitions of "rural." Rural Small Town Can Anal Bull 2013;1-43. [Available online at:https://ageconsearch.umn.edu/bitstream/28031/1/ wp020061.pdf; cited 4 June 2018]

27. Starfield B, Weiner J, Mumford L, Steinwachs D. Ambulatory care groups: a categorization of diagnoses for research and management. Health Serv Res 1991;26:53-74

28. Kaplan EL, Meier P. Nonparametric estimation from incomplete observations. J Am Stat Assoc 2012;6:128-32.

29. Roos NP, Mustard CA. Variation in health and health care use by socioeconomic status in Winnipeg, Canada: does the system work well? Yes and no. Milbank Q 1997;75:89-111.

30. Katz SJ, Hofer TP, Manning WG. Hospital utilization in Ontario and the United States: the impact of socioeconomic status and health status. Can J Public Health 1996;87:253-6.

31. Cairney J, Arnold R. Social class, health and aging: socioeconomic determinants of self-reported morbidity among the noninstitutionalized elderly in Canada. Can J Public Health 1996;87:199-203.

32. Mackillop WJ, Zhang-Salomons J, Boyd CJ, Groome PA. Associations between community income and cancer incidence in Canada and the United States. Cancer 2000;89:901-12.

33. Boyd C, Zhang-Salomons JY, Groome PA, Mackillop WJ. Associations between community income and cancer survival in Ontario, Canada, and the United States. JClin Oncol 1999;17:2244-55.

34. Byers TE, Wolf HJ, Bauer KR, et al. on behalf of the Patterns of Care Study Group. The impact of socioeconomic status on survival after cancer in the United States: findings from the National Program of Cancer Registries Patterns of Care Study. Cancer 2008;113:582-91.

35. Williams J, Clifford C, Hopper J, Giles G. Socioeconomic status and cancer mortality and incidence in Melbourne. Eur J Cancer 1991;27:917-21.

36. Faggiano F, Zanetti R, Costa G. Cancer risk and social inequalities in Italy. J Epidemiol Community Health 1994;48:447-52. 
37. Van Loon AJ, Goldbohm RA, Van den Brandt PA. Socioeconomic status and breast cancer incidence: a prospective cohort study. Int J Epidemiol 1994;23:899-905.

38. Brewster DH, Thomson CS, Hole DJ, Black RJ, Stroner PL, Gillis CR. Relation between socioeconomic status and tumour stage in patients with breast, colorectal, ovarian, and lung cancer: results from fournational, population based studies. BMJ2001;322:830-1.

39. Macleod U, Ross S, Fallowfield L, Watt GC. Anxiety and support in breast cancer: is this different for affluent and deprived women? A questionnaire study. Br J Cancer 2004;91:879-83.

40. Munro AJ, Bentley AH. Deprivation, comorbidity and survival in a cohort of patients with colorectal cancer. Eur J Cancer Care (Engl) 2004;13:254-62.

41. RamirezAJ, Westcombe AM, Burgess CC, Sutton S, Littlejohns P, Richards MA. Factors predicting delayed presentation of symptomatic breast cancer: a systematic review. Lancet 1999;353:1127-31.

42. Ciccone G, Prastaro C, Ivaldi C, Giacometti R, Vineis P. Access to hospital care, clinical stage and survival from colorectal cancer according to socio-economic status. Ann Oncol 2000;11:1201-4.

43. Alter DA, Franklin B, Ko DT, et al. Socioeconomic status, functional recovery, and long-term mortality among patients surviving acute myocardial infarction. PLoS One 2014;8:e65130.

44. McIsaac W, Goel V, Naylor D. Socio-economic status and visits to physicians by adults in Ontario, Canada. J Health Serv Res Policy 1997;2:94-102.
45. Marmot MG. Stress, social and cultural variations in heart disease. J Psychosom Res 1983;27:377-84.

46. Singh S, Law C. Multidisciplinary reference centers: the care of neuroendocrine tumors. J Oncol Pract 2010;6:e11-16.

47. Feinberg Y, Law C, Singh S, Wright FC. Patient experiences of having a neuroendocrine tumour: a qualitative study. Eur J Oncol Nurs 2013;17:541-5.

48. Junor EJ, Hole DJ, Gillis CR. Management of ovarian cancer: referral to a multidisciplinary team matters. $\mathrm{Br} J$ Cancer 1994;70:363-70.

49. Forrest LM, McMillan DC, McArdle CS, Dunlop DJ. An evaluation of the impact of a multidisciplinary team, in a single centre, on treatment and survival in patients with inoperable non-small-cell lung cancer. Br J Cancer 2005;93:977-8.

50. Gutierrez JC, Perez EA, Moffat FL, Livingstone AS, Franceschi D, Koniaris LG. Should soft tissue sarcomas be treated at high-volume centers? An analysis of 4205 patients. Ann Surg 2007;245:952-8.

51. Mustard CA, Derksen S, Berthelot JM, Wolfson M. Assessing ecologic proxies for household income: a comparison of household and neighbourhood level income measures in the study of population health status. Health Place 1999;5:157-71.

52. Krieger N. Overcoming the absence of socioeconomic data in medical records: validation and application of a censusbased methodology. Am J Public Health 1992;82:703-10. 


\section{APPENDIX A: INTERNATIONAL CLASSIFICATION OF DISEASES, REVISION 9, AND INTERNATIONAL CLASSIFICATION OF DISEASES FOR ONCOLOGY CODES USED FOR THE DATA ANALYSIS}

\section{Cohort Creation}

A neuroendocrine tumour diagnosis was defined using the codes in the International Classification of Diseases, 9th revision (ICD-9), and the first 4 digits of the codes in the International Classification of Diseases for Oncology (ICD-O), as abstracted in the Ontario Cancer Registry (Tables AI-AIII). The population was defined using either of the criteria.

TABLE AI Inclusion criteria

\begin{tabular}{|c|c|c|c|}
\hline \multicolumn{4}{|c|}{ ICD-9 codes } \\
\hline 259.2 & Carcinoid syndrome & 209.63 & Benign carcinoid stomach \\
\hline 209.20 & Malignant carcinoid primary site unknown & 209.00 & Malignant carcinoid small intestine NOS \\
\hline 209.25 & Malignant carcinoid foregut NOS & 209.01 & Malignant carcinoid duodenum \\
\hline 209.26 & Malignant carcinoid midgut NOS & 209.02 & Malignant carcinoid jejunum \\
\hline 209.27 & Malignant carcinoid hindgut NOS & 209.03 & Malignant carcinoid ileum \\
\hline 209.29 & Malignant carcinoid other site & 209.40 & Benign carcinoid small intestine NOS \\
\hline 209.60 & Benign carcinoid primary site unknown & 209.41 & Benign carcinoid duodenum \\
\hline 209.65 & Benign carcinoid foregut NOS & 209.42 & Benign carcinoid jejunum \\
\hline 209.66 & Benign carcinoid midgut NOS & 209.43 & Benign carcinoid ileum \\
\hline 209.67 & Benign carcinoid hindgut NOS & 209.4 & Benign carcinoid of the small intestine \\
\hline 209.69 & Benign carcinoid other site & 209.12 & Malignant carcinoid appendix \\
\hline 209.29 & Malignant carcinoid of other sites & 209.0 & $\begin{array}{l}\text { Malignant carcinoid tumours of the appendix, large intestine, } \\
\text { and rectum }\end{array}$ \\
\hline 209.3 & Malignant poorly differentiated neuroendocrine carcinoma & 209.10 & Malignant carcinoid large intestine NOS \\
\hline 209.30 & $\begin{array}{l}\text { Malignant poorly differentiated neuroendocrine carcinoma, } \\
\text { any site }\end{array}$ & 209.12 & Malignant carcinoid cecum \\
\hline 209.21 & Malignant carcinoid bronchus/lung & 209.13 & Malignant carcinoid ascending colon \\
\hline 209.22 & Malignant carcinoid thymus & 209.14 & Malignant carcinoid transverse colon \\
\hline 209.62 & benign carcinoid bronchus/lung & 209.15 & Malignant carcinoid descending colon \\
\hline 209.61 & benign carcinoid thymus & 209.16 & Malignant carcinoid sigmoid colon \\
\hline 157.4 & Islets of Langerhans, any part of the pancreas & 209.17 & Malignant carcinoid rectum \\
\hline 211.7 & Benign neoplasm of islets of Langerhans & 209.24 & Malignant carcinoid kidney \\
\hline 209.23 & Malignant carcinoid stomach & & \\
\hline \multicolumn{4}{|c|}{ ICD-O codes } \\
\hline 8150 & Islet cell carcinoma & 8240 & Carcinoid \\
\hline 8151 & Insulinoma & 8241 & Enterochromaffin cell carcinoid \\
\hline 8152 & Glucagonoma & 8242 & Enterochromaffin-like cell tumours \\
\hline 8153 & Gastrinoma & 8244 & Composite carcinoid \\
\hline 8154 & Mixed islet-cell/exocrine adenocarcinoma & 8245 & Adenocarcinoid \\
\hline 8155 & VIPoma & 8246 & Neuroendocrine carcinoma \\
\hline 8156 & Somatostatinoma & 8249 & Atypical carcinoid \\
\hline 8157 & Enteroglucagonoma & & \\
\hline
\end{tabular}

ICD-9 = International Classification of Diseases, Revision 9; ICD-O = International Classification of Diseases for Oncology; NOS = not otherwise specified. 
TABLE AII Exclusion criteria

\begin{tabular}{llrl}
\hline & & ICD-O codes & \\
\hline 8002 & Malignant tumour, small cell type & 8000 & Neoplasm \\
8040 & Tumorlet & 8010 & Epithelial tumor \\
\hline 8041 & Small cell carcinoma NOS & 8070 & Squamous cell carcinoma \\
8042 & Oat cell carcinoma & 8140 & Adenoma \\
8043 & Small cell carcinoma NOS, fusiform cell type & 8341 & Papillary carcinoma \\
8044 & Small cell carcinoma NOS & 8481 & Mucinous adenocarcinoma \\
8045 & Combined small cell carcinoma & 8500 & Ductal carcinoma \\
\hline 8013 & Large cell neuroendocrine carcinoma of the lung & 9364 & Peripheral neuroectodermal tumor \\
\hline 8700 & Pheochromocytoma & 9370 & Chordoma \\
8680 & Paraganglioma & 9990 & No microscopic neoplasm \\
8693 & Extra-adrenal paraganglioma & 8243 & Goblet cell carcinoid \\
8510 & Medullary carcinoma of the thyroid & & \\
\hline
\end{tabular}

ICD-O = International Classification of Diseases for Oncology; NOS = not otherwise specified.

TABLE AIII Definition of metastatic disease

\begin{tabular}{|c|c|c|c|}
\hline \multicolumn{4}{|c|}{ ICD-9 codes } \\
\hline 196.0 & Malignant neoplasm lymph-head/neck & 198.1 & Secondary malignant neoplasm urinary NEC \\
\hline 196.1 & Malignant neoplasm lymph-intrathor & 198.2 & Secondary malignant neoplasm skin \\
\hline 196.2 & Malignant neoplasm lymph intra-abd & 198.3 & Secondary malignant neoplasm brain/spine \\
\hline 196.3 & Malignant neoplasm lymph-axilla/arm & 198.4 & Secondary malignant neoplasm nerve NEC \\
\hline 196.5 & Malignant neoplasm lymph-inguin/leg & 198.5 & Secondary malignant neoplasm bone \\
\hline 196.6 & Malignant neoplasm lymph-intrapelv & 198.6 & Secondary malignant neoplasm ovary \\
\hline 196.8 & Malignant neoplasm lymph node-mult & 198.7 & Secondary malignant neoplasm adrenal \\
\hline 196.9 & Malignant neoplasm lymph node NOS & 198.81 & Secondary malignant neoplasm breast \\
\hline 197.0 & Secondary malignant neoplasm lung & 198.82 & Secondary malignant neoplasm genital \\
\hline 197.1 & Secondary malignant neoplasm mediastinum & 198.89 & Secondary malignant neoplasm NEC \\
\hline 197.2 & Secondary malignant neoplasm pleura & 199.0 & Malignant neoplasm disseminated \\
\hline 197.3 & Secondary malignant neoplasm resp NEC & 199.1 & Malignant neoplasm NOS \\
\hline 197.4 & Secondary malignant neoplasm small bowel & 209.70 & Secondary neuroendocrine tumour, unspecified site \\
\hline 197.5 & Secondary malignant neoplasm large bowel & 209.71 & Secondary neuroendocrine tumour of distant lymph nodes \\
\hline 197.6 & Secondary malignant neoplasm peritoneum & 209.72 & Secondary neuroendocrine tumour of liver \\
\hline 197.7 & Secondary malignant neoplasm liver & 209.73 & Secondary neuroendocrine tumour of bone \\
\hline 197.8 & Secondary malignant neoplasm GI NEC & 209.74 & Secondary neuroendocrine tumour of peritoneum \\
\hline 198.0 & Secondary malignant neoplasm kidney & 209.79 & Secondary neuroendocrine tumour of other sites \\
\hline \multicolumn{4}{|c|}{ ICD-10 codes } \\
\hline $\mathrm{C} 77$ & Secondary and unspecified malignant neoplasm of lymph nodes & C79 & Secondary malignant neoplasm of other and unspecified sites \\
\hline C78 & $\begin{array}{l}\text { Secondary malignant neoplasm of respiratory and digestive } \\
\text { organs }\end{array}$ & & \\
\hline
\end{tabular}

ICD-9 = International Classification of Diseases, Revision 9; ICD-O = International Classification of Diseases for Oncology; NEC = neuroendocrine carcinoma; NOS = not otherwise specified. 